\title{
PDPH BY USING SAME GMUGE OF NEEDLES
}

\section{DR. M.ASGHAR KHAN}

Department of Anesthesia

Combined Military Hospital

Quetta Cantt.

\section{DR. M. DANISH HANIF}

Department of Anesthesia

Combined Military Hospital

Quetta Cantt.

\author{
DR. M.RASHID IQBAL \\ Department of Anesthesia \\ Combined Military Hospital \\ Quetta Cantt.
}

ABSTRACT... There is increase incidence of Lower Segment Caesarian section (LSCS) being performed under sub-arachnoid block (SAB) because it is relatively safe. One of the complications of SAB is Post Dural Puncture Headache (PDPH) which is very distressing to the patient. Objective: To observe the incidence of PDPH by using two different types of spinal needle of 25 gauge in females undergoing LSCS under SAB. Currently, in our setup $25 \mathrm{G}$ cutting (quincke) spinal needle is routinely used. Study design: Randomized controlled trial. Setting: Department of Anesthesia, Officers Family Hospital, Rawalpindi Cantt. Duration of study: 6 months from 15 February 2011 to 15 July 2011. Material and Method: 100 pregnant patients undergoing elective $C D$ under spinal anaesthesia were randomized into two groups $A \& B$. Group A received SAB with $25 \mathrm{G}$ Quincke needle; Group B- received SAB with $25 \mathrm{G}$ pencil-point needle. Follow up was done upto 72 hours after the surgery. Data obtained through study was analysed through computer software SPSS version 12. Quantitative variables like age, weight and height are presented as mean and standard deviation. The frequency of PDPH was qualitatively analysed in percentage. The frequency of PDPH was compared between two groups with the application of Chi-square as test of significance at $P$-value $<0.05$. Results: It was found that the incidence of PDPH with Quincke (cutting tip) needle was significantly higher (7.\%) as compared to pencil point needle (0\%). Conclusion: pencil-point spinal needle is associated with lesser incidence of PDPH and should be preferred to Quincke needle to achieve SAB in patients undergoing LSCS.

Keywords: PDPH, LSCS, Quincke cutting tip spinal needle and pencil point spinal needle.

\section{INTRODUCTION}

There is increase incidence of Lower segment Caesarian section (LSCS) being performed under sub-arachnoid block $(S A B)^{1,2}$ because it is relatively safe. One of the complications of SAB is Post Dural Puncture Headache (PDPH) which is very distressing ${ }^{1}$ to the patient and inadvertently prolong stay in the hospital causing burden to both the patient and health care facility in terms of economy ${ }^{1}$ and longer ${ }^{5}$ hospital bed occupancy.

Any breach of the dura may result in a postdural puncture headache $(\mathrm{PDPH})^{5}$. PDPH is bilateral, frontal or retroorbital, occipital and extends into the neck ${ }^{7}$. It may be throbbing or constant and associated with photophobia and nausea ${ }^{1,7}$. The hallmark of PDPH is its association with body position ${ }^{6,7}$. The pain is aggravated by sitting or standing and relieved or decreased by lying down flat. The onset of headache is usually $12-72 \mathrm{~h}$ following the procedure ${ }^{1,2,7}$. PDPH result from leakage of CSF from a dural defect and decreased intracranial pressure. Loss of CSF at a rate faster than it can be produced causes traction ${ }^{1,2,7}$ on structures supporting the brain, particularly the dura and tentorium. Increased traction on blood vessels also likely contributes to the pain.

Factors $^{1,2,7}$ that increase the risk of PDPH include young age, female sex, and pregnancy. Amount of CSF leak depends upon the size of Dural tear which in turn depends upon the size and shape of spinal needle being used to perform the sub arachnoid block. Fine (pencil point) and non cutting tip spinal needles tend to leave small puncture in Dura and causes less incidence of PDPH ${ }^{1,2,3,7}$. Quincke point needles cut the dural fibres and may cause persistent dural tears, while non-cutting or pencil point spinal needles may spread dural fibers which come back to their normal position thereby decreasing CSF loss after dural puncture reducing the incidence of PDPH. Hence, a great degree of variation is seen in incidence of PDPH with different designs of 
spinal needles ${ }^{1}$. As female sex and young age are purported risk factors, this complication is common in the obstetrical population, who frequently receive spinal analgesia and anaesthesia during labour and delivery. The reason for this may be the extreme changes in intra abdominal pressure during labor which could influence cerebrospinal fluid pressure, the rapid changes in blood volume following delivery, the dehydration during labor and the lesser attention paid to fluid replacement parenterally after delivery. But the exact reason is still not known ${ }^{1}$. Similarly type of diseases and surgery also effect on the rate of occurrence of PDPH, like more incidence is with c-section ${ }^{3}$. Hence, we decided to conduct a study to compare the incidence of PDPH using 25G Quincke vs $25 \mathrm{G}$ pencil-point spinal needles in patients undergoing lower segment cesarean section to assess which design and gauge is most appropriate for obstetric patients ${ }^{1}$. Currently, in our setup 25G cutting (quincke) spinal needle is routinely used.

\section{MATERIALAND METHOD}

\section{Study Design}

Randomized controlled trial

\section{Setting}

Department of Anesthesia, Officers Family Hospital, Rawalpindi Cantt.

\section{Duration of Study}

6 months from 15February 2011 to 15 July 2011.

\section{Sample Size}

The calculated study sample size was determined to be approximately 50 patients in each group with $1 \%$ margin of error and $80 \%$ power of study. Group A will receive quincke needle for performing $S A B$ and group $B$ will receive pencil point needle.

\section{Sampling Technique}

Non probability, consecutive

\section{INCLUSION CRITERIA}

1. Females undergoing LSCS under SAB who agreed to participate in the research.
2. ASAl andll status.

3. Age 18-35 years.

4. Primigravida.

\section{EXCLUSION CRITERIA}

1. Failed block or multiple pricks.

2. Prior history of headache of any origin.

3. Patient who had experience of PDPH in the past.

4. Anticipated difficulty while performing $S A B$ (deformity spine ,backache)

\section{DATA COLLECTION PROCEDURE}

After approval from hospital ethical committee and written informed consent, admitted patients fulfilling the inclusion criteria were included in the study. The entire sample was randomly allocated into 2 groups by draw method under supervision of trainee researcher from a box containing 50 slips labeled A and 50 slips labeled B. Group $A$ received $25 G$ quincke needle and group $B$ received 25G pencil-point needle for $S A B$. The demographic information including age, parity, height, weight etc were also recorded.In the pre-operative area, each patient was preloaded with $10 \mathrm{ml} / \mathrm{kg}$ Ringer lactate before the procedure with $18 \mathrm{G}$ cannula. Under strict antiseptic measure, after identification of appropriate intervertebral space, SAB was performed using $2.0 \mathrm{ml}$ of hyperbaric bupivacain solution in sitting position. Patients were immediately placed in supine position with a wedge placed under right hip. After assessment of adequacy of block, surgical team was allowed to proceed. Patients were monitored intra-operatively with NIBP (taken every 5 minutes), Oxygen saturation with pulse oximeter, and ECG. After the procedure each patient was followed up for 72 hours and asked about any headache by the trainee researcher. Headache at any point in the follow up period of 72 hours was considered positive which was recorded in a specially designed Performa. Data was recorded by trainee researcher.

\section{DATAANALYSIS PROCEDURE}

Data obtained through research was analysed through computer software SPSS version 12. Quantitative variable like age, weight and height were presented as mean and standard deviation. The frequency of PDPH was qualitatively analysed in percentage. The frequency of PDPH was compared between two groups with the 


\begin{tabular}{lcc}
\multicolumn{3}{c}{ Table I. Demographic distribution } \\
& Group A & Group B \\
& Mean (SD) & Mean (SD) \\
Age (yrs) & $27.97 \pm 3.80$ & $26.13 \pm 4.22$ \\
Height $(\mathrm{cm})$ & $166.74 \pm 4.31$ & $167.61 \pm 3.94$ \\
Weight $(\mathrm{kg})$ & $68.00 \pm 3.65$ & $67.10 \pm 3.61$ \\
application of cross-tabulation. &
\end{tabular}

\section{RESULTS}

In our study, a total of 100 patients undergoing lower segment cesarean section were given sub-arachnoid block. The mean age, height and weight were approximately similar in both the groups. (Table-I)

The study showed that $7 \%$ of the patients in group $A$ developed PDPH whereas in group $B, 0 \%$ of the patients developed PDPH which when compared with group $A$. (Table-II) The time of onset of PDPH was day 1 in 6 of the patients was day 2 in only 1 patient in group $A$ who developed PDPH, whereas no patient among the 50 pts developed PDPH in group B.In group A, majority of the patients i.e. 57.14\%, who developed PDPH, the duration of headache was 3 days. In group $A$, the highest proportion of the patients i.e. $57.14 \%$ had no radiation of headache. The commonest side effect was nausea and vomiting.In group A, $14.28 \%$ of the patients had side effects in the form of nausea, vomiting and dizziness. None of the patients had tinnitus, hearing loss, neck rigidity and blurring of vision as side effects.

\section{DISCUSSION}

Post dural puncture headache (PDPH) is the most common and very distressing ${ }^{1,2}$ complication of the subarachnoid block. It may lead to patient discomfort, prolonged hospitalizations and may even require an epidural blood patch for its resolution".

The mechanism of PDPH is believed to be sagging of the contents of the skull because of decrease in CSF pressure. So PDPH is also known as low pressure headache. The main etiology of this condition is the loss of CSF through the dural rent created by the spinal
Table II. Post dural puncture headache

$\begin{array}{lcc} & \text { Group (A) \% } & \begin{array}{c}\text { Group (B) } \\ \% \text { Incidence }\end{array} \\ \text { Incidence } & 7(7 \%) & 0(0 \%) \\ \text { Onset } & 6(6 \%) & 0(0 \%) \\ \text { Day 1 } & 1(1 \%) & 0(0 \%) \\ \text { Day 2 } & & \\ \text { Location } & 2(28.57 \%) & 0(0 \%) \\ \text { Temporal } & 1(14.28 \%) & 0(0 \%) \\ \text { Occipital } & 4(57.14 \%) & 0(0 \%) \\ \text { Frontal } & & \\ \text { Quality } & 2(28.57 \%) & 0(0 \%) \\ \text { Dull ache } & 5(71.42 \%) & 0(0 \%) \\ \text { Throbbing } & & \\ \text { Side effects } & 1(14.28 \%) & 0(0 \%) \\ \text { Nausea } & 1(14.28 \%) & 0(0 \%) \\ \text { Vomiting } & 1(14.28 \%) & 0(0 \%) \\ \text { Dizziness } & 11(14.28 \%) & 0(0 \%) \\ \text { Duration (days) } & 22(28.57 \%) & 0(0 \%) \\ & 34(57.14 \%) & 0(0 \%)\end{array}$

needle leading to decrease in the CSF pressure. There are various factors related to PDPH such as age of the patient, gender, needle size, needle tip design, direction of the bevel of the needle and the number of attempts at dural puncture, the most important being spinal needle tip design. The incidence of PDPH is higher in female than males and, it is more common in reproductive age group \& pregnant females than the elderly. The reason for this may be the extreme changes in intra abdominal pressure during labor which could influence cerebrospinal fluid pressure, the rapid changes in blood volume following delivery, the dehydration during labor and the lesser attention paid to fluid replacement parenterally after delivery.

The overall incidence of distressing post spinal headache has varied from $0 \%$ to $37.2 \%$, as reported by various authors. In our study, out of the total 100 patients, 7 patients developed PDPH. All were of group $A$ in which 25G Quincke spinal needle was used.This value came out to be highly statistically significant. A cutting type of needle inserted through the dural wall tears off a number 
of fibres in the wall and a permanent opening in it is ensured. The puncture site has typical crescent like appearance produced by the cutting type of needle. The anatomical feature of dura is such that longitudinal dispersion of its fibre plus a copious interspersion of elastic fibres keeps the hole open once the dural fibre are cut. Carrie suggested the use of a pencil point lumbar puncture needle and the tip of the pencil point needle separates the longitudinal dural fibres without producing serious injury. When the needle is withdrawn the fibres return to a state of close approximation, thereby closing the rent and preventing any CSF leakage.

A meta-analysis done by Halpern and Presto showed that non-cutting needles (Whitacre) for spinal anaesthesia produced a lower incidence of PDPH than cutting needles (Quincke). The usual onset of PDPH is on 12 to 72 hours after subarachnoid block. In our study, out of nine patients of group A who developed PDPH, six patients had its onset on day 1 and only one had its onset on day 2 whereas in group $B$, no one developed PDPH. PDPH can also be associated with side effects like nausea, vomiting, dizziness, tinnitus, hearing loss or blurring of vision. Cases have been reported when PDPH was associated with neck rigidity. In our study, two out of seven patients who developed PDPH had associated nausea, vomiting and dizziness whereas none of the patients complained of hearing loss, blurring of vision or neck rigidity.

\section{Conclusion}

From our study, we concluded that 25G Whitacre pencil point needle is associated with no incidence of $\mathrm{PDPH}$ $(0 \%)$ than $25 \mathrm{G}$ Quincke cutting needle $(7 \%)$ in pregnant females under going elective lower segment cesarean section and since the failure rate with $25 \mathrm{G}$ spinal needles is $0 \%, 25 G$ needles Whitacre spinal needles may be the preferred for sub-arachnoid block in cesarean section patients ${ }^{1}$.

\section{Copyright@16 May, 2012}

\section{REFERENCES}

1. Oberoi R, Kaul TK, Singh MR, Grewal A, Dhir R. Incidence of Post Dural Puncture Headache. 25 Gauge Quincke VS 25 Gauge WhitacreNeedles. J Anaesth Clin Pharmacol 2009; $25: 420-22$.

2. Shaikh JM, Memon A, Memon MA, Khan M. Post dural puncture headache after spinal anaesthesia for caesarean section: a comparison of $25 \mathrm{~g}$ Quincke, 27 $\mathrm{g}$ Quincke and $27 \mathrm{~g}$ Whitacre spinal needles. J Ayub Med Coll Abbottabad. 2008;20:10-3.

3. Malik TM, Iqbal A, Khan MA. Post spinal headache; comparing needles of 25 and 27 gauges for incidence of post spinal headache. Professional Med J 2007;14:441-7.

4. Fyneface-Ogan S, Mato CN, Odagme MT. Post-dural puncture headache following caesarean section in Nigerian parturients: A comparison of two spinal needles. Niger Postgrad Med J. 2006 ;13:200-2.

5. Tejavanija $S$, Sithinamsuwan $P$, Sithinamsuwan $N$, Nidhinandana S, Suwantamee J. Comparison of prevalence of post-dural puncture headache between six hour- supine recumbence and early ambulation after lumbar puncture in thai patients: A randomized controlled study. J Med Assoc Thai. 2006 ;89:814-20.

6. Gosch UW, Hueppe M, Hallschmid M, Born J, Schmucker $\mathrm{P}$, Meier T. Post-dural puncture headache in young adults: comparison of two small-gauge spinal catheters with different needle design. $\mathrm{Br} \mathrm{J}$ Anaesth. $2005 ; 94: 657-61$.

7. Wu CL,Rowlingson AJ,Cohen SR, Michaels RK, Courpas GE, Joe EM, Liu SS. Gender and post dural puncture headache. Anesthesiology 2006;105:613-8.

\footnotetext{
Article received on: $\quad$ 05/04/2012 Accepted for Publication: 16/05/2012 Received after proof reading: $\quad$ 00/00/0000

Correspondence Address:

Maj. Dr. Rashid lqbal

Classified Anesthetist

$\mathrm{CMH}$, Quetta Cantt.

rashid_203@yahoo.com

Article Citation:

Khan MA, Hanif MD, Iqbal MR. PDPH by using same gauge of needles. Professional Med J Aug 2012;19(4):553-556.
} 